\title{
Edukasi Kader Kesehatan Remaja Untuk Memaksimalkan Fungsi Usaha Kesehatan Sekolah (UKS) di SMK Muhammadiyah 1
}

\author{
Samarinda \\ Purwo Setiyo Nugroho', Deddy Alif Utama ${ }^{2}$ \\ ${ }^{1}$ Program Studi Kesehatan Masyarakat, Universitas Muhammadiyah Kalimantan Timur \\ 2Program Studi Kesehatan Lingkungan, Universitas Muhammadiyah Kalimantan Timur \\ e-mail : ${ }^{* 1}$ purwo.skm@umkt.ac.id, ${ }^{2}$ deddyalif@umkt.ac.id
}

\begin{abstract}
Clean and healthy life behavior in the school setting needs to be implemented to ensure the health of students. Seeing the potential of diseases that threaten students, it is deemed necessary to have preventive efforts actively carried out by students at school. The existence of School Primary Health Unit in Senior High School of Muhammadiyah 1 Samarinda is felt to be still not optimal. It is necessary to have adolescent health cadres who are able to move their peers to live clean and healthy in the school environment. To increase the capacity of these youth health cadres, it is felt necessary to have an intervention in the form of soft skills training and outreach to all school members of the importance of the role of the School Primary Health Unit in improving health education through the Clean and Healthy Behavior standards in the school environment. The method used in the activities is the method of lectures, questions and answers and the practice of becoming a peer educator. There was an increase in knowledge after providing education for peer educators and students. The need for continuous monitoring by the school is felt necessary to ensure the running of this system.
\end{abstract}

Keywords : Knowledge, behavior, school primary health unit

\begin{abstract}
Abstrak. Perilaku hidup bersih dan sehat pada tatanan sekolah perlu diterapkan untuk menjamin kesehatan siswa yang memiliki potensi besar terserang penyakit. Melihat adanya potensi penyakit yang mengancam siswa, maka dirasa perlu adanya upaya preventif yang dilakukan secara aktif oleh siswa di sekolah. Adanya Usaha Kesehatan Sekolah (UKS) di SMK Muhammadiyah 1 Samarinda dirasa masih belum maksimal. Dalam pelaksanaan UKS ini, perlu adanya kader kesehatan remaja yang berkemampuan untuk menggerakkan rekan sebayanya untuk hidup bersih dan sehat di lingkungan sekolah, sehingga akan muncul lingkungan sekolah yang sehat dan nyaman bagi siswa. Untuk meningkatkan kapasitas kader kesehatan remaja ini dirasa perlu adanya intervensi berupa pelatihan softskill dan sosialisasi kepada seluruh warga sekolah akan pentingnya peran UKS dalam meningkatkan derajar kesehatan melalui standar Perilaku Hidup Bersih dan Sehat di lingkungan sekolah. Metode yang digunakan dalam kegiatan program pelatihan kader remaja kesehatan ini adalah metode ceramah, tanya jawab dan praktik menjadi peer educator. Ada peningkatan pengetahuan setelah pemberian edukasi bagi peer educator dan siswa SMK Muhamamdiyah 1 Samarinda. Perlunya monitoring berkelanjutan oleh pihak sekolah dirasa perlu untuk menjamin berjalannya sistem pengelolaam Usaha Kesehatan Sekolahini.
\end{abstract}

Kata Kunci : Pengetahuan, perilaku, usaha kesehatan sekolah 


\section{Pendahuluan}

Kualitas kesehatan suatu bangsa ditentukan oleh kualitas kesehatan masyarakatnya, hal ini tergambarkan pada indikator Indeks Pembangunan Manusia (IPM) yang terdapat tiga indikator kemajuan suatu negara, yakni indikator ekonomi, pendidikan (angka melek huruf) dan kesehatan. Sadar atas pentingnya akan kesehatan, maka pemerintah mengeluarkan Undang-undang No 36 tentang Kesehatan (Diana dkk, 2014). Peningkatan kualitas kesehatan masyarakat hendaknya di lakukan sejak dini. Hal ini dapat dilakukan pada tingkat sekolah, karena pada dasarnya sekolah merupakan wadah pendidikan siswa yang didalamnya diajarkan banyak hal termasuk dunia kesehatan (Arikunto, 2010). Pentingnya kesehatan dalam sekolah tertuang dalam Undang-undang Kesehatan tersebut pasal 79 terkait kesehatan sekolah. Pelaksanaan kesehatan di sekolah diatur pula dalam Peraturan Menteri Kesehatan (PERMENKES) No. 2269/Menkes/Per/X/2011 tentang penyelenggaraan Perilaku Hidup Bersih dan Sehat diberbagai tatanan termasuk Institusi Pendidikan (Daramusseng dan Julianti,2019).

Perilaku hidup bersih dan sehat pada tatanan sekolah dilakukan untuk menjamin kesehatan para siswa agar terhindar dari risiko penyakit akibat lingkungan sekolah. Salah satu yang masih teringat dibenak masyarakat Samarinda adalah ditemukannya permen yang mengandung narkoba di beberapa lingkungan sekolah di Samarinda. Jajanan ini berbentuk permen lolipop yang dijual berkisar Rp, 1000 hingga Rp. 3000 (Fivi dkk, 2014). Hal ini sangat merugikan bagi siswa karena akan menganggu kesehatannya kelak. Risiko lingkunagn lainnya adalah persebaran penyakit demam berdarah, dimana nyamuk Aedes Aegypti memiliki kebiasaan aktif pada pukul 06.00 pagi hingga 17.00 sore. Hal ini mengindikasikan bahwa terdapat peluang risiko terkena penyakit demam berdarah pada siswa sekolah pada aktivitasnya (Karaeng skk, 2016).

Melihat adanya potensi penyakit yang mengancam siswa dari berbagai penjuru, maka dirasa perlu adanya upaya preventif yang dilakukan secara aktif oleh siswa di sekolah (Gomo dkk, 2013). Adanya Usaha Kesehatan Sekolah di SMK Muhammadiyah 1 Samarinda dirasa masih belum maksimal karena fungsi UKS nya berupa tempat untuk mengobati dan tempat istirahat jika ada siswa yang sakit (Dinas Kesehatan Kota Samarinda, 2016). Padahal lebih dari itu, fungsi UKS bertujuan untuk memupuk kebiasaan hidup sehat dan mempertinggiderajat kesehatan peserta didik yang mencakup memiliki pengetahuan, sikap, dan keterampilan prinsip hidup sehat, sehat fisik, mental serta lingkungan. 


\section{Metode}

Metode yang digunakan dalam kegiatan program pelatihan kader remaja kesehatan ini adalah metode ceramah, tanya jawab dan praktik menjadi peer educator. Bentuk kegiatan yang dilaksanakan dalam program edukasi kader kesehatan remaja adalah sebagai berikut (Purwandari,2015):

1. Pretest pengetahuan PHBS tatanan sekolah untuk mengetahui gambaran awal pengetahuan siswa

2. Pemberianmateri mengenaiPHBStatanansekolahkepadasiswauntukmemperkayailmu

3. Pemberian pelatihan kader kesehatan remaja dalam mengelola Usaha Kesehatan Sekolah SMK Muhammadiyah 1 Samarinda.

4. Praktik menjadi peereducator untuk mendukung dalam menjalankan program Usaha Kesehatan Sekolah SMK Muhammadiyah 1Samarinda.

5. Posttest pengetahuan PHBS tatanan sekolah untuk mengukur pengetahuan setelah diberikan pendidikankesehatan

\section{Hasil dan Pembahasan}

Pengabdian masyarakat pada tahap pertama pada tanggal 25 April 2019 dilakukan pretest pada siswa untuk mengetahui pengetahuan awal siswa. Intervensi kesehatan berupa pemberian edukasi kesehatan dilakukan menggunakan media LCD melalui metode diskusi. Untuk mengevaluasi intervensi tersebut, dilakukan pengukuran pengetahuan siswa melalui pretest, sehingga akan diketahu apakah ada peningkatan pengetahuan atau tidak. Kegiatan dilanjutkan dengan diskusi tanya jawab mengenai kesehatan sekolah, banyak siswa yang tertarik akan diskusi ini, hal ini terbukti dengan banyaknya pertanyaan yang dilontarkan. Adapun hasil pengukuran pengetahuan siswa (pretest dan posttest) dapat dilihat pada tabel berikut (Lumongga dan Syahrizal, 2013): 
Tabel 1. Proporsi Tingkat Pengetahuan Siswa Mengenai Perilaku Hidup Bersih dan Sehat di Lingkungan Sekolah

\begin{tabular}{|c|c|c|c|c|c|c|c|}
\hline \multirow[t]{3}{*}{ Jenis Tes } & \multicolumn{4}{|c|}{ Tingkat Pengetahuan } & \multirow{3}{*}{$\begin{array}{l}\text { \% Kenaikan } \\
\text { (Pre - Post) }^{*}\end{array}$} & \multicolumn{2}{|c|}{ Total } \\
\hline & \multicolumn{2}{|c|}{ Cukup } & \multicolumn{2}{|c|}{ Kurang } & & & \\
\hline & $\mathbf{n}$ & $\%$ & $\mathbf{n}$ & $\%$ & & $\mathbf{n}$ & $\%$ \\
\hline Pretest & 27 & 45,8 & 32 & 54,2 & \multirow{2}{*}{55,55} & 59 & 100 \\
\hline Posttest & 42 & 71,2 & 17 & 28,8 & & 59 & 100 \\
\hline
\end{tabular}

Sumber: Data Primer, 2019

Tabel 1 menunjukkan bahwa dari 59 siswa yang mengikuti kegiatan ini, sebesar $54,2 \%$ siswa masih memiliki tingkat pengetahuan dasar yang kurang mengenai perilaku hidup bersih dan sehat di lingkungan sekolah. Sedangkan sisanya yaitu sebanyak 45,8\% telah memiliki tingkat pengetahuan yang cukup. Berbeda dengan hal tersebut, setelah dilakukan sosialisasi mengenai perilaku hidup bersih dan sehat di lingkungan sekolah, terjadi perubahan proporsi dimana sebesar $71,2 \%$ tingkat pengetahuan siswa telah berada pada kategori cukup. Sedangkan sisanya yaitu sebanyak 28,8\% memiliki tingkat pengetahuan yang kurang. Hal ini berarti terjadi peningkatan proporsi jumlah siswa dengan kategori pengetahuan cukup sebesar 55,55\%.

Selanjutnya, karena data terdistribusi tidak normal (p.value <0,05), maka dalam melihat adanya perubahan antara pengetahuan mengenai perilaku hidup bersih dan sehat di lingkungan sekolah sebelum dan setelah pelaksanaan kegiatan sosialisasi, maka dilakukan uji wilcoxon. Dengan hasil sebagai berikut:

Tabel 2. Perubahan Tingkat Pengetahuan Siswa Mengenai Perilaku Hidup Bersih dan Sehat di Lingkungan Sekolah

\begin{tabular}{|c|c|c|c|c|}
\hline \multicolumn{2}{|c|}{ Tingkat Pengetahuan } & \multirow{3}{*}{$\Delta$} & \multirow{3}{*}{$\begin{array}{l}\text { \% Kenaikan } \\
\text { (Pre -Post)* }^{*}\end{array}$} & \multirow{3}{*}{ p.value } \\
\hline Pretest & Posttest & & & \\
\hline $\bar{x}$ & $\bar{x}$ & & & \\
\hline $8,22 \pm 1,532$ & $8,85 \pm 1,047$ & $0,63 \pm 1,484$ & 7,66 & 0,001 \\
\hline
\end{tabular}

\section{Sumber: Data Primer, 2018}

Tabel 2 diatas menjelaskan bahwa nilai rata-rata tingkat pengetahuan siswa sebelum dilakukan sosialisasi adalah 8,22 sedangkan pada saat setelah dilakukan sosialisasi adalah 8,85 . Hal ini berarti terjadi peningkatan tingkat pengetahuan rata-rata siswa sebesar 7,66\%. Nilai p.value adalah 0,001 $(<0,05)$. Sehingga dapat disimpulkan bahwa terdapat perbedaanyang signifikan antara pengetahuan mengenai perilaku hidup bersih dan sehat di lingkungan sekolah sebelum dan setelah pelaksanaan kegiatan sosialisasi. 
Saat ini, banyak sekolah yang memiliki prevalensi siswa yang menderita penyakit tertentu dikarenakan pasokan air yang tidak memadai untuk kegiatan higiene dan sanitasi (terutama untuk kegiatan mencuci tangan). UNICEF memperkirakan bahwa lebih dari separuh institusi pendidikan mulai dari tingkat dasar hingga menengah di seluruh dunia kekurangan toilet yang bersih, air minum, dan pembelajaran tentang higiene sanitasi untuk seluruh muridnya. Air bersih dan sanitasi sangat penting untuk melindungi kesehatan dan kemampuan mereka untuk belajar. Dalam hal ini, air bersih dan sanitasi yang memadai sangat penting seperti halnya buku teks. Ketersediaan air bersih dan sanitasi memiliki dampak pada kesehatan termasuk di dalamnya kesehatan fisik, mental, dan sosial serta pembangunan ekonomi dan politik yang tonggaknya dimulai dari pelajar sebagai generasi penerus bangsa (Rifki, 2014).

Selain itu, adanya kontaminasi bakteri patogen yang didukung oleh kurangnya perilaku hidup bersih dan sehat (PHBS) seperti merokok dan aktivitas fisik yang kurang seperti jarang berolahraga makin memperparah kondisi kurangnya fasilitas air bersih dan WC tersebut tersebut. Data dari Global Youth Tobbaco Survey (GYTS 2014) menyatakan bahwa 20,3\% anak sekolah merokok. Sementara itu, menurut data Survei Sosial Ekonomi Nasional (Susenas), Survei Kesehatan Rumah Tangga (SKRT) dan Riset Kesehatan Dasar (Riskesdas) menunjukkan terjadinya peningkatan prevalensi perokok usia 15 tahun ke atas yaitu antara 27 - 36,3\% dari tahun sebelumnya. Selanjutnya, walaupun prevalensi anak usia sekolah dasar dan sekolah menengah pertama yang melakukan aktivitas fisik masih dalam kategori yang baik, namun untuk penduduk usia 15 tahun keatas termasuk di dalamnya anak usia sekolah menengah atas, 77,3\% diantaranya kurang melakukan aktivitas fisik (Rufiati dkk, 2011).

Korelasi positif ditemukan pula antara tingkat pengetahuan dengan perilaku hidup bersih dan sehat di lingkungan sekolah. Dalam beberapa penelitian, individu yang memiliki pengetahuan tentang perilaku hidup bersih dan sehat, cenderung akan melakukan tindakan terkait higiene dan sanitasi agar terhindar dari beberapa penyakit seputar saluran pencernaan. Penelitian di Minahasa Utara, mendapatkan hasil bahwa terdapat hubungan yang bermakna antara pengetahuan siswa dengan perilaku hidup bersih dan sehat, dalampenelitian tersebut sebagian besar siswa yang memiliki pengetahuan yang baik tentang perilaku hidup bersih dan sehat juga melakukan berbagai tindakan yang mendukung upaya dalam menjaga kesehatan diri mereka seperti mencuci tangan sebelum makan, membuang sampah pada tempatnya dan sebagainya. Hasil penelitian ini sejalan dengan penelitian di Kalimantan Barat, dimana terdapat hubungan yang signifikan antara 
pengetahuan ibu terkait perilaku hidup bersih dan sehat dengan kasus diare pada anak umur 1-4 tahun di daerah tersebut. Ibu yang tidak memiliki pengetahuan yang cukup terkait PHBS cenderung tidak menerapkan PHBS di kehidupannya sehari-hari, sehingga secara tidak langsung anaknya memiliki risiko yang lebih besar dalam menderita diare (Santrock, 2011). Hal tersebut didukung oleh hasil penelitian di Kabupaten jember, dimana secara statistik membuktikan ada hubungan yang signifikan antara perilaku cuci tangan yang baik dan benar dengan insiden diare $(\mathrm{p}=0,005$ dan $\mathrm{r}=0,792)$. Penelitian lainnya menyatakan bahwa orang yang tidak melakukan perilaku hidup bersih dan sehat memiliki risiko 3,5 kali lebih besar dalam menderita diare. Salah satu contoh kebiasaan yang berhubungan dengan kebersihan perorangan dan berpengaruh besar dalam penularan kuman diare adalah mencuci tangan dengan sabun, terutama sesudah buang air besar, sebelum dan setelah makan. Mencuci tangan dengan sabun bahkan dapat menurunkan angka kejadian diare sebesar 47\% (Solehati dkk, 2015).

Salah satu faktor penting dalam perubahan pengetahuan adalah keberhasilan dalam pemberian informasi kepada target atau peserta. Beberapa penelitian terkait pengaruh penyuluhan sebagai salah satu media informasi terhadap perubahan perilaku hidup bersih dan sehat mengungkapkan bahwa terdapat perbedaan yang signifikan antara pengetahuan dan sikap sebelum dan sesudah pemberian penyuluhan (Stang, 2014). Sebagai contoh, para guru di suatu sekolah di Kabupaten Bandung, setelah dilakukan edukasi, mereka termotivasi untuk melakukan pemeriksaan kebersihan diri kepada siswa dengan benar dan berkelanjutan Syahribulan dkk, 2012). Para siswa selanjutnya mengalami perubahan pola personal hygiene kearah yang lebih baik setelah dilakukan evaluasi selama tiga bulan berturut-turut (Zitty dkk,2015).

Berikut dokumentasi dalam kegiatan edukasi mengenai perilaku hidup bersih dan sehat pada siswa dan peer educator SMK Muhammadiyah 1 Samarinda.

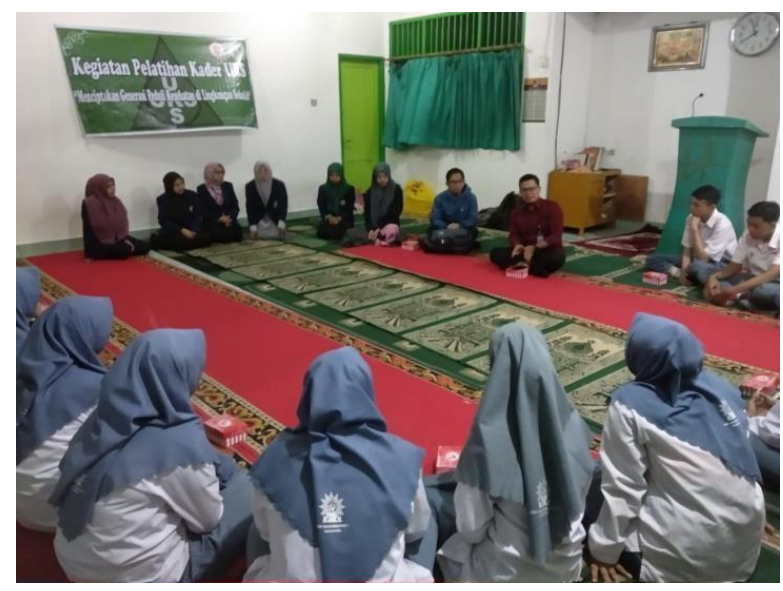

6 | Edukasi Kader Kesehatan... 
Gambar 1. Pelatihan Peer Educator dalam mengelola Usaha Kesehatan Sekolah

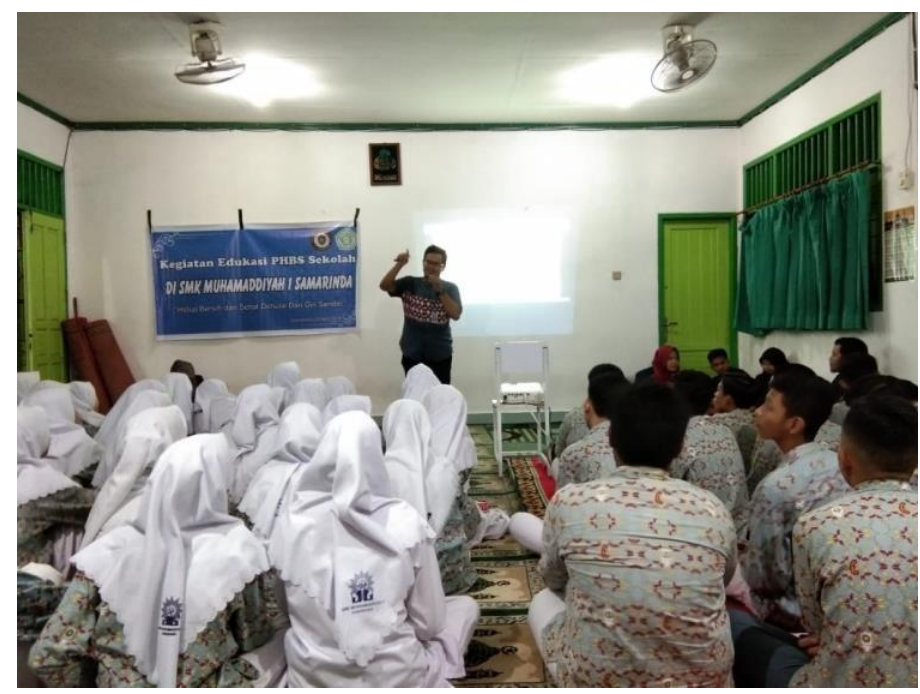

Gambar 2. Edukasi kesehatan pada siswa SMK Muhammadiyah 1 Samarinda

\section{Simpulan}

Institusi pendidikan dipandang sebagai sebuah tempat yang strategis untuk mempromosikan pendidikan kesehatan, dimana para peserta didik dapat diajarkan tentang tujuan perilaku hidup bersih dan sehat, serta konsekuensinya. Perilaku Hidup Bersih dan Sehat (PHBS) di institusi pendidikan merupakan kebutuhan mutlak seiring munculnya berbagai penyakit yang sering menyerang anak usia sekolah, yang ternyata umumnya berkaitan dengan Perilaku Hidup Bersih dan Sehat (Rifki, 2014). PHBS disekolah merupakan sekumpulan perilaku yang dipraktekkan oleh peserta didik, guru dan masyarakatlingkungansekolahatasdasarkesadaransebagaihasilpembelajaran,sehinggasecara mandiri mampu mencegah penyakit, meningkatkan kesehatannya, serta berperan aktif dalam mewujudkan lingkungan sehat. Terwujudnya PHBS pada tatanan sekolah yang didukung oleh sarana dan prasarana higiene dan sanitasi yang memadai akan berpengaruh dalam meningkatkan kesadaran siswa, karena usia sekolah merupakan usia yang rentandan peka terhadap stimulus sehingga lebih mudah diarahkan dan ditanamkan kebiasaan yang baik termasuk perilaku hidup bersih dan sehat (Daramusseng dan Julianti,2019).

\section{Daftar Pustaka}

Arikunto, Suharsimi. (2010). Prosedur Penelitian Pendekatan Praktik. Jakarta: Rhineka Cipta.

Daramusseng, Andi., Julianti, Tri Budi. (2019). “Program Sanitarian Cilik Di SDN 011Samarinda Sebagai Sarana Edukasi Pola Perilaku Hidup Bersih Dan Sehat Pada Masyarakat."Jurnal Pengabdian pada Masyarakat 
2(4).http://ppm.ejournal.id/index.php/pengabdian/article/view/132.

Diana FM, Susanti F, Irfan A. 2014 Pelaksanaan Program Perilaku Hidup Bersih dan Sehat (PHBS) di SD Negeri 001 Tanjung Balai Karimun. Jurnal Kesehatan Masyarakat. Vol 8: Hal 46-51.

Fivi Melva Diana., Fatrina Susanti., Asep Irfan. (2014). "Pelaksanaan Program PerilakuHidup." 8(1): 46-51.

Gomo MJ, Umboh JM, Pandelaki. 2013. Gambaran Perilaku Hidup Bersih Dan Sehat (Phbs) Sekolah Pada Siswa Kelas Akselerasi Di SMPN 8 Manado. Ebiomedik. Volume 1. No.1.

Karaeng,V. D., ddk. (2016). Gambaran Perilaku Hidup Bersih dan Sehat (PHBS) pada Siswa Sekolah Dasar Negeri Inpres Karatung Kecamatan Menganitu Kabupaten Sangihe. Manado: Fakultas Kesehatan Masyarakat Universitas Sam Ratulangi.

Kesehatan, Dinas, and Kota Samarinda. (2016). "Profil Kesehatan Kota Samarinda Tahun 2016."

Lumongga N dan Syahrial. 2013. Promosi Kesehatan dan Biostatistika. Pengaruh Penyuluhan Dengan Metode Ceramah Dan Diskusi Terhadap Peningkatan Pengetahuan Dan Sikap Anak Tentang Phbs Di Sekolah Dasar Negeri Kelurahan Namogajah Kecamatan Medan Tuntungan Tahun 2013. Kebijakan, Promosi Kesehatan dan Biostatistik. Volume 2.No.1.

Purwandari R, Ardiana. 2015. Hubungan antara perilaku mencuci tangan dengan insiden diare pada anak usia sekolah di Kabupaten Jember. Jurnal Keperawatan; Volume. 4. No. 2.

Rifki, E. F. (2014). Gambaran Pengelolaan Program Pendidikan KecakapanHidup Sosial untuk Anak Usia 4-6 Tahun. Semarang: Fakultas KesehatanMasyarakat-UNDIP.

Rufiati AM, Raharjo BB, Indrawati. 2011. Pengaruh Metode Permainan Find Your Mate Terhadap Peningkatan Pengetahuan Kader Posyandu. Jurnal Kemas; Volume 6, No. 2.

Santrock, J. (2011). Life-Span Development Ed.13. New York: The McGraw-HillCompany.

Solehati T, Susilawati S, Lukman M, Kosasih. 2015. Pengaruh edukasi terhadap pengetahuan dan skill guru serta personal hygiene siswa SD. Jurnal Kemas; Volume 11, No. 1:135-43.

Stang. (2014). Praktis Penentuan Uji Statistik dalam Penelitian Kesehatan dan Kedokteran.Jakarta: Mitra Wacana Medika.

Syahribulan, Biu FM, Hassan MS. 2012. Waktu Aktivitas Menghisap Darah Nyamuk Aedes Aegypti dan Aedes Albopictus di Desa Pa'Lanassang Kelurahan Barombong Makassar Sulawesi Selatan. Jurnal Ekologi Kesehatan. Vol 11: Hal306-14.

Zitty A.R Koem., Barens Joseph., Recky C. Sondakh. (2015). “Hubungan Antara Pengetahuan Dan Sikap Dengan Perilaku." 4(4): 290-94. 